' Universidade Nacional de Quilmes, Argentina

silvismiet@gmail.com

Silvina Smietniansky'

\title{
TEMPO, ORALIDADE E ESCRITA: A SOCIEDADE HISPANO-COLONIAL ATRAVÉS DO ESTUDO DE UM PROCEDIMENTO JUDICIAL*
}

Este trabalho volta o olhar sobre as colônias sul-americanas da Monarquia hispânica e busca aproximar-se etnograficamente de alguns dos modos em que as sociedades locais concebiam, experimentavam e representavam o tempo. Para isto, baseia-se no estudo do caso resultante do juicio de residencia dirigido a um governador da província de Tucumán em meados do século XVIII. Executado por ordem e em nome do Rei, este processo definiu o espaço ritual em que relatos orais, testemunhos escritos e ações rituais terminaram por converter-se em um documento de $7 \mathrm{mil}$ páginas que interroga o passado, isto é, o trabalho dos funcionários locais. Contudo, sendo um documento que transcende o momento de sua produção, ele comporta também uma perspectiva do futuro. A partir deste campo etnográfico, a construção social do tempo e as relações entre oralidade e escrita delineiam as problemáticas que interessa explorar.

Como mostraram Émile Durkheim e Marcel Mauss, resulta impossível avançar em uma exploração do tempo sem levar em conta os condicionamentos sociais em que certas representações se constroem (Durkheim, 2007 [I9I2]; Durkheim \& Mauss, I97I [I903]). A antropologia, como a história, registraram a existência de outras formas de organização social e econômica que remetem a maneiras diferentes de contar o tempo, contribuindo, neste trajeto, para relativizar e historicizar nossas próprias noções (Leach, I97 I [196I]; Evans-Pritchard, I977 [1940]; Le Goff, I983 [I978]; Thompson, I967; Sahlins, I988 [I985]; Geertz, I992 [1973]). Por sua vez, como expõem os estudos de Reinhart Koselleck (2006 
[1979]) e Johannes Fabian (I983), a reflexão sobre o próprio ofício de historiadores e antropólogos, os modos de construir o objeto de estudo e de aproximar-se dele ao longo do desenvolvimento histórico de cada disciplina foram incorporados na análise desta problemática, revelando como certas concepções e manejos do tempo condicionam o olhar do analista.

O estudo do tempo possibilita múltiplas abordagens que dependem tanto das opções teóricas como do campo etnográfico da pesquisa. Este trabalho propõe uma aproximação etnográfica ao material histórico e recorta a análise do tempo por meio de uma abordagem que coloca a questão da linguagem em primeiro lugar. Examino fontes escritas em que se descobrem os traços orais e rituais que marcaram sua elaboração; isto é, o mesmo corpus documental oferece a possibilidade de abordar o tempo mediante a problematização de diferentes registros. Jack Goody (2000) assinala que o caráter lábil, variável e efêmero da oralidade se opõe à permanência e fixação que implica a fabricação de um documento escrito que, por sua vez, no futuro, poderá constituir critério de autoridade e referência para as práticas que descreve. Por outro lado, indica que os atributos da oralidade e da escrita divergem nos modos de vincular e integrar o passado e o presente; a "cultura oral" orienta uma percepção do passado em função do presente e a escrita possibilita o desenvolvimento de um pensamento histórico (Goody \& Watt, 2003 [1968]). Em seu estudo sobre os Paéz, povo indígena da Colômbia, Joanne Rappaport (I987) põe em questão essa dicotomia ao descrever como essa sociedade recorre a um ou outro registro, dependendo dos motivos e dos contextos de atuação. Na defesa de sua autonomia frente à sociedade dominante, a escrita ocupa um lugar central, enquanto, internamente, a manutenção da identidade comunitária se estabelece através da oralidade. A distinção entre os domínios orais e escritos é parte de um processo histórico, isto é, "ela se molda por sua necessidade tanto de funcionar na sociedade dominante como de manter uma identidade distinta" (Rappaport, I987: 57, tradução editorial). Também sob uma postura crítica, Ruth Finnegan (I988) sustenta que oralidade e escrita não constituem duas esferas separadas, e, sim, modos que interagem e se afetam mutuamente, e cujas formas variam em diferentes culturas e períodos. ${ }^{\mathrm{I}}$

Estas observações indicam a necessidade de atender aos contextos históricos e sociais particulares, sugerindo que um enfoque etnográfico pode contribuir nesta tarefa. Este enfoque parte do reconhecimento da universalidade da experiência humana e, ao mesmo tempo, entende que a possibilidade de nos aproximar das perspectivas nativas está mediada pelo diálogo que estabelecemos entre as ditas perspectivas e nossos próprios marcos culturais e analíticos, os quais se redefinem e ampliam nesse processo (Peirano, I995). o mundo colonial hispânico que exploramos não foi pensado, construído ou experimentado a partir dos conceitos aos quais recorremos para nos referir a ele e buscar compreendê-lo. Por isto a necessidade de atender às categorias locais que, inscritas nas fontes coloniais, definem nossa rota de acesso a estas 
outras formas de representar e perceber o tempo, e também de problematizar os usos e as implicações do registro oral e escrito. ${ }^{2}$

Em particular, nossa aproximação aos modos nativos de conjugar oralidade e escrita está influenciada pela perspectiva de Stanley Tambiah (I985) que, no estudo do ritual, incorpora ao enfoque etnográfico as contribuições de Roman Jakobson, Charles Peirce e John Austin. O interesse em compreender as implicações que revestem os relatos orais e os textos escritos na produção e conceituação do passado, assim como os efeitos que a mesma ação de produzir um documento acarreta na percepção e constituição de um horizonte de tempo por vir, se articula em torno destas linhas teóricas que enfatizam o caráter performativo da linguagem e sua dimensão pragmática. Trata-se, neste ponto, de desvendar o caráter das ações de relatar, escrever e produzir um objeto, para além de sua função referencial (Austin, I975). ${ }^{3}$

\section{O ESTUDO DO TEMPO EM UM JUICIO DE RESIDENCIA}

Por azar e por intenção, chegou até nós uma série de materiais escritos que permitem explorar alguns aspectos da vida dos "vizinhos" (vecinos) e dos funcionários do governo colonial, que integravam o grupo de maior status nessa dinâmica e complexa configuração social.4 Examino a documentação de caráter oficial produzida no juicio de residencia instruído ao coronel Juan Victorino Martínez de Tineo em I763-I764. ${ }^{5}$ Estes processos, oficialmente ordenados pela Coroa, tinham como fim julgar o trabalho dos funcionários depois da conclusão de seus mandatos e puni-los no caso de comprovação do descumprimento de seus deveres, além de contribuir para a melhora do funcionamento das instituições de governo a partir do reconhecimento de suas deficiências. Ademais, como vários trabalhos sugerem, também as residencias e outros procedimentos similares - como é o caso da visita - podem ser entendidos como rituais que contribuíram para a criação e reprodução da ordem colonial, reafirmando a presença do Rei sobre seus domínios e atualizando o vínculo com seus súditos (Guevara Gil \& Salomon, I994; Herzog, 2000; Smietniansky, 2013).

Entretanto, a lente monárquica não aparecia imediatamente, logo depois que o funcionário tivesse finalizado seu mandato. O juicio de residencia examinado teve início dez anos depois de Tineo terminar suas funções. As testemunhas foram então consultadas sobre suas ações passadas, bem como as de todos aqueles que ocuparam cargos no cabildo de cada cidade durante o período de I749-I754, que corresponde ao mandato do governador. ${ }^{6}$ Cabe então perguntar de que modo as memórias e as experiências dos entrevistados foram rearranjadas sob os critérios cronológicos e temáticos impostos pela residencia. E, também, que eficácia teria um julgamento que se realizara tanto tempo depois de acontecidos os fatos que viria a escrutinar, quando muitos teriam prosseguido no exercício de novos cargos, migrado ou, inclusive, falecido? 
Se estas perguntas nos situam diante do passado que a residencia indagava, outras articulam esta retrospectiva com o tempo do julgamento e com o horizonte futuro. Nas residencias elaboravam-se extensos expedientes nos quais se registrava a declaração oral de mais de cem testemunhos. Tratava-se, então, de fixar e conservar o presente (o julgamento que se estava executando) em um apoio material. Nesse processo a residencia pareceria atuar mediando o passado e o presente de modo singular, conduzindo a palavra desde a oralidade até a escrita. Se a análise do conteúdo não se pode separar da análise da forma que o constitui (Tambiah, I985), interessa indagar quais mudanças de sentido e implicações essa variação no canal utilizado resulta para a mensagem, e de que modo os tempos do processo judicial que "estava acontecendo" se rearranjaram sob a estrutura do registro escrito.

Em geral, diante de um texto escrito, nosso primeiro objetivo é conseguir ler e dar sentido à concatenação de palavras e frases ali dispostas. Tratando-se de um documento elaborado há tanto tempo, mesmo para os leitores de espanhol, é necessário aprender a reconhecer uma caligrafia que é, em parte, diferente da atual. Este conhecimento é fundamental se quisermos identificar os referentes desse texto, isto é, se entendermos o texto, literalmente, como algo que foi construído para ser lido. Este parece ser um suposto básico. Que outro sentido ou objetivo teria um texto além de ser lido?

Dissemos que o documento resultante da residencia do Tineo era composto por 7 mil laudas e este fato, na verdade, faz arrefecer a motivação de lê-lo. Seguidamente nos deparamos com as mesmas perguntas, as mesmas fórmulas, com as testemunhas repetindo as mesmas frases. Se quiséssemos conservar somente o conteúdo - apenas o referente - sabemos que restariam apenas umas mil páginas. Mas a lógica desta escrita é precisamente aquela oposta a um padrão que enfatiza a função denotativa, o discurso direto e a economia do texto.

Pode-se alegar que um procedimento judicial tem sempre por objetivo fundamentar com precisão as decisões que um magistrado tomará (ou recusará adotar). Não obstante, a extensão sem limites preestabelecidos dessa escrita se contrapõe à sequência temporal fixa, condensada e limitada em dois meses, período que durava a realização da residencia como um ritual. Partindo das funções de linguagem do modelo de Jakobson (I97I), cabe então se perguntar se a extensão do texto não conspira contra sua função referencial.?

\section{OS TEMPOS DA ESCRITA E O “TEMPO DA RESIDENCIA"}

O tempo de realização da residencia era preciso e bem sinalizado, tal qual um ritual que a própria sociedade recorta como um evento diferente do cotidiano (Tambiah, I985; Peirano, 200I). Na praça pública e nos locais comuns de cada cidade noticiava-se à população o começo do julgamento e a lista dos fun- 
cionários que seriam residenciados. Cumprindo as ordens de Baltazar Azebey, nomeado por cédula do Rei em qualidade de juez superior da residencia dirigida a Tineo e encarregado de seguir o julgamento na cidade de Salta, os seis juízes comissionados para as cidades restantes publicaram o decreto de residencia em 22 de janeiro de i764. Os tempos locais e ordinários de cada cidade foram, deste modo, realocados em função de uma temporalidade paralela (a publicação foi feita nesse dia em todas as cidades e assim, também, sincronicamente, o resto do julgamento), de caráter regional (a província) e marcada fortemente pela presença do Rei (a residencia em si mesma reafirmava sua presença e autoridade sobre estes domínios).

Contudo, há outro atributo que define o tempo da residencia: seu caráter efêmero, com data de expiração incluída. A sequência temporal do julgamento, em que se podem distinguir quatro fases durante dois meses, compreendia: os preparativos e a abertura do julgamento, a "pesquisa secreta", a "pesquisa pública" e a sentença. As demandas que se iniciassem contra os imputados fora desse período não tinham validade legal. De fato, finalizado este tempo e determinada a sentença, já não haveria júri de residencia ao qual antepor uma reclamação. Na residencia tudo parece haver sido perecível: a comissão do juiz, que o designava para este lugar, expirava ao final do processo; os espaços habilitados para realizar o julgamento voltavam a seus usos ordinários; o ritmo imposto por esse acontecimento que envolvia os habitantes das sete cidades tucumanas acabava e, assim, cada uma delas retomava aos seus tempos locais; as testemunhas que trabalhavam de escrivães retornavam aos seus afazeres etc. O único elemento que permanecia, ao menos dentro dos modelos formais do ritual, era o registro escrito.

Em algumas instâncias do ritual havia uma ênfase na oralidade, ainda que a escrita estivesse sempre presente. A oralidade marcava particularmente a fase de abertura: a comunidade local reunida na praça pública e lugares típicos de cada cidade, escutando a prosa oral de um relator que está comunicando as normas relativas à residencia, como será o decorrer do processo, quem serão os residenciados etc. Ainda que seja provável que essa proclamação tenha sido (ao menos em parte) resultado da leitura de um texto, a ação apresentava um caráter ritual em que a palavra falada era prioritária. De fato, a ata que certificava a realização do evento enfatizava o caráter público, cerimonial e oral do processo. Isso não desvaloriza o fato de que a escrita acompanhava, de forma permanente, como que "testemunhando" o avanço do julgamento.

Em cada cidade, o escrivão - ou, em sua ausência, duas testemunhas que atuavam na ausência do mesmo - anotava o depoimento de uma série de vizinhos. Essas declarações individuais, pronunciadas perante o juiz, formavam parte do tempo presente do julgamento, este tempo da ação-que-está-em-curso, embora se trate de um discurso sobre o passado: as perguntas, organizadas em um texto e lidas pelo escrivão ou pelo magistrado, a que devem 
responder, remetem às ações do governo que aproximadamente dez anos antes levaram a cabo o governador e os funcionários locais. Isto é, o documento escrito que ali se está produzindo constitui um testemunho de um discurso oral, que por sua vez é testemunho de um feito passado.

No marco ritual da residencia se reinstalavam fatos acontecidos durante o mandato do governador residenciado; assim, a residencia de Tineo limitou sua investigação ao período de I749-I754. Para se referir a este período de tempo os declarantes, imputados e magistrados, falavam de "o tempo da residencia", "no tempo dessa residência", "no tempo de Tineo", "o tempo de dito governador", entre outras fórmulas. ${ }^{8} \mathrm{~A}$ diligência sobre esse passado era conduzida por meio do exame de duas classes de provas: por um lado, a declaração de testemunhas e, por outro, o exame que o juiz fazia dos livros do cabildo (atas das sessões privadas, livros de renda, pleitos seguidos pelos alcaides etc.) elaborados nessa etapa. Os juízes também avaliavam o estado do edifício capitular e da cadeia. Os relatórios indicam como tinham sido elaborados, com o olhar voltado ao uso que poderia se dar em uma residencia futura, que se encarregaria de avaliar os acontecimentos desse tempo "atual". Inclusive, quando nos cabildos havia ficado depositada uma cópia do informe e a sentença correspondente à residencia anterior - a antecessora, como a denominavam -, os juízes comparavam as deficiências registradas com os resultados da investigação que estavam administrando. Em muitos casos, chamavam a atenção para o fato de que permaneciam os mesmos problemas e de que os funcionários não haviam cumprido as ordens que os magistrados passados estabeleceram para sanar ditas deficiências. Nestas instâncias vemos, então, que a ação de escrever, ao longo do julgamento, vai mediando entre o passado que narram os depoimentos e o futuro, que antecipavam enquanto eram escritos.

O julgamento impunha uma seleção sobre os eventos não só sob um critério temporal, como também em outro, temático. Durante a residencia dirigida a Tineo, em todas as cidades, com algumas variações, as testemunhas foram consultadas a partir de um mesmo questionário classificado em blocos de perguntas, referidas aos distintos cargos residenciados. Sobre um total aproximado de II5 perguntas, 55 focavam nas ações do governador e seus tenentes, I 2 sobre a conduta dos regedores e funcionários com voto no cabildo, 8 eram relativas aos alcaides ordinários, I 3 referidas aos escrivães, I I aos empregados subalternos e outro tanto para os procuradores, os defensores de menores, os alcaides da Santa Irmandade (Alcaldes de la Santa Hermandad), os "alcaides de águas" (alcaldes de aguas) e os protetores de índios (protectores de indios). Os temas mais importantes sobre os quais as testemunhas eram consultadas questionavam se os imputados haviam procedido com negligência e omissão no cumprimento das funções específicas de cada um dos ofícios, e se haviam incorrido em suborno ou em práticas ilícitas dirigidas à obtenção de benefícios pessoais, tanto para o residenciado como para seus parentes e 
amigos. Desta maneira, o julgamento sistematizava e organizava os relatos a partir da estrutura do corpo capitular - os ofícios que o compunham - e de uma série de tópicos.

Vemos então que nesse transitório tempo da realização da residencia, esta se ocupa de recuperar relatos sobre o passado e fixá-los por escrito, e esse passado resulta organizado - ou melhor, construído -, em princípio a partir de duas variáveis que parecem nos guiar em uma mesma direção interpretativa. Por um lado, "o tempo da residencia" corresponde ao mandato do governador e, nesse caso, poderíamos pensar que é o tempo do Estado que mais se impõe. Não é o tempo das memórias e experiências individuais, nem aquele que se traça a partir de um determinado acontecimento criminal que motiva o desenvolvimento de um julgamento. É um tempo que tem a aspiração de unificar histórias e relatos próprios de cada cidade, o que sugere a pretensão aglutinadora de um poder central. Por outro lado, os relatos se organizavam segundo a estrutura do governo local, e isto é indicador de que as memórias das testemunhas resultam modeladas e compartimentadas sob a classificação institucional. São os tempos do sistema político-jurídico que, de raiz castelhana e imposto sob o domínio hispânico, foi tomando forma no decorrer das conjunturas e agentes locais, e organizando a vida da sociedade colonial.

Embora estes relatos fossem declarados e registrados dez anos depois dos eventos que descrevem, os juízes não manifestavam a existência de inconsistências ou dificuldades que o julgamento viesse a detectar sobre o tempo passado; isto é, suas condutas não indicam hesitações em torno da "veracidade" destes relatos. Isto nos leva a perguntar se a busca da "verdade" a que se refere o juiz Baltazar Azebey aponta efetivamente para o reconhecimento dos fatos "tal qual sucederam" uma década atrás. É esta a pretensão do juicio de residencia? Em seu relatório final ao Conselho das Indias, Azebey assinala que o tempo destinado à residencia é limitado para que possa percorrer a província e fazer como se deveria:

sendo sete cidades, por mais vigilância e dedicação que tenha um juiz, não é possível ver tudo em tão pouco tempo para cumprir com sua obrigação e desencargo de sua consciência, nem os pobres, principalmente os índios de encomienda, e mulheres desvalidas expõem suas queixas aos comissionados, que são do mesmo pays, e emparentados aos juízes ordinários, temerosos de não serem ouvidos e de experimentar maiores extorsões como experimentei depois de sentenciada a residencia com a ocasião de haver visitado algumas cidades. ${ }^{9}$

A ineficácia da residencia em reunir o tipo de informação que supostamente orientava sua execução se contrapõe ao cuidado na execução do prazo e julgamento. Estes últimos, sim, parecem ter sido alcançados. No mesmo sentido, o conteúdo poderá ser insuficiente para reconhecer a situação da província - se considerarmos os dizeres de Azebey. Contudo, esse aspecto contrasta com o produto final escrito que serve como registro desse mundo social. A extensão 
do documento, sua organização, a sistematização dos dados, as redundâncias das formas escritas, a quantidade de declarações transcritas resultam em um único texto denso e extenso que, à primeira vista, pode nos fazer pensar que ali encontraremos quase uma fotografia da província de Tucumán em meados do século XVIII.

\section{SOBRE A RELATIVA DISTÂNCIA DO PASSADO}

A participação no juicio de residencia marcava o pertencimento ao grupo de maior status da sociedade colonial: indivíduos residenciados, testemunhas e juízes compartilhavam todos da condição de vizinhança (vecinanza), e recorriam a ela em cada apresentação, indicando, assim, esse pertencimento. Por um lado, este processo colocava em cena os funcionários do governo - que eram objeto da investigação -, e era nesse sentido um julgamento sobre o poder político local. Por outro lado, Azebey ordenou aos juízes subdelegados que recebessem cada um o depoimento de ao menos 16 testemunhas, resultando um total de I43 declarações. ${ }^{\text {IO }} \mathrm{A}$ autoridade e a fidedignidade do relato residiam, em parte, da condição social das testemunhas, isto é, quem deviam qualificar como "personas de graduación ciencia y consciencia y de buena reputación". ${ }^{\text {II }}$ A tomada dos depoimentos iniciou-se em 23 de janeiro e se desenvolveu paralelamente em todas as cidades, durando aproximadamente 15 dias.

O interrogatório tinha um caráter reservado e estavam presentes o juiz, o declarante e o escrivão (ou, caso este faltasse, duas testemunhas indicadas pelo juiz). A partir de seu registro escrito, podemos reconstruir a sequência de etapas e suas fórmulas típicas. Na fase de abertura se registrava a data e o lugar, e se apresentavam o juiz (nome, cargo e instrumentos jurídicos que lhe permitiam agir no processo) e a testemunha (nome, cargo, condição de vizinhança e relações de parentesco com os residenciados). Em seguida, se realizava o "juramento de verdade" que legitimava as declarações das testemunhas e cujo registro escrito revela alguns rastros orais desse evento: jurou por Deus, realizou "um sinal da Cruz" e "prometeu dizer a verdade em tudo o que soubesse". Enquanto ritual (Tambiah, I985), o juramento estava dotado de uma força performativa que realizava esse compromisso ao enunciar e ser confirmado (pelo juiz ou pelo escrivão) o "juramento de verdade" em condições adequadas. ${ }^{12}$ Também era eficaz ao recriar um marco sagrado em cujo contexto os dizeres que seriam oferecidos pelo declarante se legitimavam e assumiam validez. Além disso, essa eficácia foi transferida ao texto escrito que, ao informar sobre a execução correta do ritual através de sua descrição, dotou de legitimidade a declaração que finalmente ficou registrada no expediente.

Pouco depois dessa abertura ritual, o juiz interrogava a testemunha com um questionário preestabelecido que estava dividido em blocos de perguntas correspondentes a cada cargo de governo: liam-se as perguntas, que eram 
respondidas oralmente e o escrivão registrava as respostas. Finalmente, como um encerramento, a testemunha ratificava seu depoimento (recorrendo ao juramento proclamado no começo do interrogatório e validando, assim, sua eficácia), o escrivão certificava através de sua palavra o ocorrido no interrogatório e assinavam o juiz, o escrivão e a testemunha.

Este era o contexto formal, segundo relata o registro escrito, em que a testemunha oferecia seu depoimento. Em alguns casos, as respostas eram muito concisas, pautadas pelo esquecimento de um tempo que se caracterizava como distante. Em outras ocasiões, o minucioso relato sobre determinados acontecimentos do passado que a testemunha tinha bem presente no momento do julgamento pareceria reduzir essa distancia. Este último é o caso de alguns dos relatos referentes à política militar ofensiva do governador contra as populações indígenas do Chaco. A formação de reducciones indígenas na fronteira chaqueña, a construção e a manutenção dos fortes e presídios e as sistemáticas campanhas contra os índios foram tópicos mencionados de modo recorrente nos depoimentos. Algumas testemunhas basearam seus depoimentos de caráter mais geral em "ter ouvido", enquanto outras, especialmente as que haviam participado junto com Tineo nas entradas ao Chaco, descreveram com detalhes e informações precisas as ações do governador. Don Martin Iturrios, vizinho de Salta, como "testemunha de vista" (testigo de vista), acreditava que "neste tempo que dito Governador havia aplicado todo zelo, desvelo e cuidado para apaziguar e aquietar esta província castigando ao Bárbaro Infiel", e, em particular, detalhou uma das invasões que o governador realizou em território indígena, na qual "avançou terra adentro no forte de San Joseph vinte léguas [e] fez o forte de Nuestra Señora do Rosario". ${ }^{13}$ Em Salta, mais que em qualquer outra cidade, os declarantes expuseram suas próprias experiências na guerra junto ao governador e o íntimo conhecimento que tinham de sua conduta. A figura de Tineo saiu favorecida nos depoimentos: seu correto e recatado modo de vida, a administração justa que trouxe às cidades e sua política militar se destacam entre outros aspectos.

Para muitas testemunhas seu mandato marcava uma nova etapa na pacificação e organização da província, muito diferente do tempo anterior. Don Miguel Pacheco de Melo, vizinho de Jujuy, destacou o trabalho que Tineo realizou na fronteira, resultando em "toda paz e quietude, que em nenhum outro tempo mereceram, senão antes de experimentarem muitos roubos, mortes e assaltos aos inimigos". Nesse mesmo tom, assinalava que "desde dito governo se goza de total paz e tranquilidade, devidas somente ao zelo e atividade deste ministro, em comparação com a insegurança que até então reinava nas fazendas e estradas". ${ }^{14}$ Outro vizinho de Jujuy, Don Antonio de Inguanzo, baseado em sua experiência, relatou as dificuldades e a insegurança que teve de superar para viajar nas estradas até o Peru, quando o governo de Tineo se iniciara. Aquele território de "fazendas ermas e despovoadas por medo do ini- 
migo, as casas abandonadas" converteu-se em outro panorama quando, tempo depois, voltou a percorrer estas mesmas rotas, porém agora "com confiança, porque os campos iam se povoando e tinham algum sossego". ${ }^{15}$ Nesta transformação destacava-se a importância da construção de fortes, promovida por Tineo. Seu mandato aparece nessa linha do tempo como um ponto que dividiria um antes e um depois. Neste aspecto, a dimensão temporal das memórias orais (realocadas sob a forma de uma declaração) parece aproximar-se da delimitação do passado que marcava a residencia, no sentido de que essa periodização imposta pelo julgamento para as testemunhas estava igualmente dotada de valores particulares que distinguiam "o tempo desta residência" do tempo de outras.

Este passado se torna mais próximo e objeto de discussão quando não ficava claro se os fatos examinados estavam compreendidos na unidade temporal que definia a residencia. Lembremos que o juiz de residencia só tinha competências para avaliar eventos acontecidos durante "o tempo da residência". O juiz subdelegado em Jujuy, Bautista de Muruaga, culpou a Don Pedro de Ereña por ter estado ausente durante o período de seu mandato como alcaide ordinário no cabildo de Jujuy. Diante de tal acusação, Ereña respondeu que esse acontecimento ficava fora da jurisdição do magistrado porque ele havia marchado até Potosí em princípios de I749, enquanto a tomada de posse de Tineo como governador - e que marcava o início do recorte sobre o qual operava a residencia - foi em junho de I749. Atendendo a esse critério, alegava que a ausência pela qual o imputavam "não me comprehende seu tempo" e, em relação a ele, "não é da jurisdição da sua comissão [a do juiz Muruaga]". ${ }^{16}$ Em uma situação similar, o general Don Louis Joseph Dias, que foi tenente do governador nas cidades de Catamarca e Tucumán durante o período de Tineo, também argumentava que alguns dos cargos que lhe foram imputados correspondiam ao tempo de outra residencia - a de Espinosa. Diante dessa declaração, Azebey respondeu que se "algumas acusações são do tempo que foi tenente do senhor governador Don Juan Alonso de Espinosa, deverá justificar plenamente que são desse tempo para não ter que se defender (pois isso deve ser feito nessa residencia)". ${ }^{\text {I7 }}$

Outras declarações enfatizavam a grande distância que caracterizava "o tempo da residência". Uma das perguntas interrogava sobre o cumprimento por parte do governador de provisões e ordens do Rei, e de decretos a favor dos índios. O capitão Don Joseph de Ojeda declarou "que não sabe nada, nem tem presente o tempo desta residencia por ter passado muito tempo", tendo respondido a 20 das 45 perguntas referentes ao trabalho do governador e dos tenentes. ${ }^{18} \mathrm{Em}$ La Rioja, das 16 testemunhas que depuseram sobre a conduta dos alcaides ordinários, 3 recorreram às fórmulas tais como "não sabe", "não lembra" ou "não tem presente" em 50\% das perguntas, 7 alegaram desconhecimento em $75 \%$ das mesmas, 2 o fizeram em $65 \%$ e 4 deles em quase $90 \%$ das indagações. O passar do tempo como argumentação para o desconhecimento aparece de forma recorrente. 
Esta gama diversa de relatos parece indicar que a residencia, em alguma medida, promovia a reconstrução de uma história e, em particular, marcava o começo e o final de experiências passadas que não foram necessariamente assim emolduradas e vivenciadas pelos atores. Deste modo, os membros da sociedade local se viam incitados (ou obrigados) a recordar e prestar conta de eventos passados sobre os quais talvez não tivessem oferecido algum relato previamente, e dos quais conservavam diversos tipos de conhecimento. Por outro lado, o uso reiterativo de fórmulas como "por ter ouvido", "por tê-lo visto" e por "ser público e notório", ou o recurso da própria experiência pessoal - categorias típicas destes processos judiciais -, revela rastros do domínio oral em que esse conhecimento circulava. Mais ainda, sugere que sob a perspectiva dos atores se distinguia uma determinada fonte de saber em que essas histórias eram difundidas e que se caracterizava pela comunicação oral. Vimos também que as respostas das testemunhas eram variadas e incluíam desde o completo desconhecimento ou esquecimento até um detalhado relato dos eventos, datas e lugares em que aconteceram. As motivações e interesses individuais e corporativos operaram provavelmente na escolha de uma ou outra resposta, seja para escapar das acusações imputadas, seja para evitar comprometer a outros com as declarações, ou para exaltar a própria figura do declarante, entre outras circunstâncias que se podem notar.

\section{DO RELATO ORAL À FIXAÇÃO ESCRITA}

Estes relatos que se apresentam sob diferentes graus de certeza e que, portanto, assinalam dúvidas sobre a veracidade do conteúdo - para os próprios declarantes - ou expõem a labilidade das memórias orais, foram todos fixados por escrito e homogeneamente sistematizados no expediente da residencia. Que características assumiu esse processo de reconversão da oralidade em escrita? Que implicações trouxe para o conteúdo dos depoimentos? A primeira questão que se deve apontar é que os expedientes das residencias examinadas adotaram uma ordem que não reproduz aquela da prática dos interrogatórios. A residencia constituía um processo integrado por uma série de etapas, durante as quais se elaboravam sucessivos escritos, formulários, depoimentos, notificações, informes de pesquisa, etc., que em seu conjunto terminavam por produzir um documento que era enviado ao Conselho das Índias e que chega até nossos dias. Pois bem, esse conjunto de autos nem sempre foi disposto de acordo com a cronologia que assumiu a residencia em cada cidade.

Vejamos o caso da residencia de Tineo. De sua investigação resulta que, enquanto todas as testemunhas foram interrogadas apenas uma vez, o depoimento de cada uma delas aparece desagregado e disposto em diferentes seções do expediente. As respostas das testemunhas foram agrupadas de acordo com cada um dos ofícios públicos residenciados. Por exemplo, nos autos realizados 
sobre alcaides ordinários juntaram-se todas as respostas que as testemunhas deram sobre as ações dos mesmos (detalhando o nome da testemunha e a data que depôs) e, da mesma maneira, o documento registra, reunidas, todas as declarações sobre Tineo. Portanto, o expediente está dividido, em primeiro lugar, por cidade (os autos dos julgamentos realizados nos respectivos distritos), e logo, "ao interior de cada cidade", distinguem-se os diferentes ofícios de governo que eram avaliados. O que interessa destacar é que nessa operação a organização do documento pulverizou o caráter processual e os tempos internos da residencia e, o resultado (escrito) se assemelha mais a uma fotografia que suprime o transcorrer do tempo. Assim, por exemplo, em Salta, sabemos que as testemunhas falaram sobre o trabalho de Tineo e logo em seguida sobre os alcaides ordinários. A seguir, vêm as respostas sobre os regedores, e assim sucessivamente. Esta forma reproduz a estrutura política local e as competências de cada cargo, mas em parte extingue a diacronia própria do desenvolvimento da residencia.

Se direcionarmos o olhar sobre as testemunhas percebemos então que, em primeiro lugar, a cadeia temporal era alterada. Por um lado, os autos escritos constituem indicadores da sequência de ações: a testemunha ingressava na sala do juiz de residencia, realizavam-se as apresentações pertinentes e se proclamava o juramento da verdade. Logo em seguida, o escrivão ou o juiz lia uma pergunta e a testemunha respondia, e assim com as mais de cem indagações que compreendia o interrogatório. Para encerrar o ato de testemunhas, como que vemos e escutamos novamente o declarante ratificar sob juramento o que havia dito e, a seguir, um a um os três indivíduos assinam o depoimento escrito do relato oral. Por outro lado, alguns aspectos desta sucessão de atos, diálogos e palavras são suprimidos em sua transposição para a escrita. O que pensar dos silêncios, das inflexões e das tensões que teriam caracterizado (podemos supor) esse interrogatório? O que acontecia antes e depois do interrogatório? Os declarantes trocavam informações? É impossível recuperar as condutas e conversas informais desse processo que ficam fora do modelo de registro que organizava a declaração. Por outro lado, também é difícil reconstruir em sua totalidade a interação formalizada desse encontro: além de o texto escrito se apresentar como "depoimento" desse evento, podemos inferir que, ao mesmo tempo que descrevia uma cena, operava fixando um modelo de como esse interrogatório deveria se conduzir (Goody, 2000).

E, como foi mencionado anteriormente, o conjunto de páginas em que estavam contidas as respostas era desagregado e suas partes dispostas de acordo com a organização prévia dos questionários, isto é, por blocos de perguntas sobre cada ofício público. Nesse sentido, uma leitura futura do expediente tanto para eles como para nós - sempre trará dificuldades para concatenar ou vincular as respostas de uma testemunha sobre os diferentes cargos, sobretudo se levarmos em conta sua extensão. Ainda cabe ressaltar que essas 
frações descontextualizadas de uma declaração eram organizadas segundo a mesma sequência de etapas que compunham o interrogatório. Isto é, quando, ao longo do documento aparecem declarações correspondentes a uma mesma testemunha - as quais na prática integraram um único depoimento oral -, cada uma delas está segmentada em três seções. Primeiro, indica-se data e lugar, autoridade do juiz competente, apresentação da testemunha e juramento de verdade; logo, figuram as respostas oferecidas pela testemunha; e, finalmente, a fórmula de ratificação da declaração e as assinaturas. Isto significa que, por um lado, a escrita recuperava o modelo formal e oral (ainda que com componentes escritos) em que se anotou a declaração da testemunha. Por outro lado, o resultado é uma escrita caracterizada pela repetição dessa forma tradicional do interrogatório em que foram realocadas as partes desagregadas de cada depoimento. É certo que seria possível voltar a juntar todas as declarações oferecidas por uma mesma pessoa, mas o ponto é que a referencialidade objetiva individual não é sua principal finalidade.

Nesse processo de escrita a indexicalidade vai se tornando obscura, ainda que o texto, como parte de um processo, possa ser tratado como um indício ou um rastro do mesmo (Peirce, I955). Ademais, nesse trajeto assistimos à fabricação de um documento que assume uma presença contundente pela sua extensão, densidade e redundância. Sem invalidar seu caráter de texto disposto para ser lido, aqui se revela um objeto material palpável, que pode ser tocado, manipulado e enviado ao próprio Rei, como um inventário que, da perspectiva de seus criadores e receptores, reunia as histórias e realidades destes distantes domínios americanos.

\section{AUTOS E RESIDENCIAS: TEXTOS E RITUAIS}

Em um artigo de I966, Edmund Leach, assimilando o rito ao mito, compara a estrutura de um ritual com a estrutura de um texto. Assim como a estrutura de um texto pode ser decomposta em parágrafos, frases, palavras etc., a estrutura de um ritual também supõe uma sequência de fases concatenadas e articuladas em diferentes níveis. Ambos os fenômenos constituem canais de comunicação. A diferença reside, segundo o autor, no caráter redundante do ritual (a mesma mensagem se transmite por diferentes canais), o que contribui para diminuir a ambiguidade e assegurar que a mensagem seja efetivamente transmitida. Por outro lado, essa redundância tem como contraponto um tipo de comunicação econômica, já que, no ritual, uma variedade de significados está condensada em um conjunto limitado de categorias. Cabe ressaltar ainda que a eficácia do ritual depende, em parte, de uma ação limitada no tempo. A dilatação desse tempo pode atentar contra os propósitos e a eficácia do ritual.

No caso que exploramos estamos diante de um ritual que, ao tempo em que se celebra, se transforma em um texto. O expediente - de forma insistente 
e repetitiva - expõe e reafirma a presença do Rei e seu domínio sobre estes territórios coloniais; uma e outra vez os depoimentos das testemunhas e o agir de alguns juízes expunham as normas que deviam respeitar os funcionários. Ler o expediente nos conduz a uma imagem da ordem em diferentes níveis: a ordem social e política examinada pela residencia e da qual as testemunhas relatam uma versão quase ideal (onde as práticas se adequam às normas), a ordem que caracterizava o desenvolvimento da residencia como um ritual e a ordem que organiza a documentação resultante.

A questão é que essa redundância, tão característica do ritual, no texto escrito acaba por desviar nossa atenção do que, de uma perspectiva referencial, seria o mais valioso em um processo judicial: o "conteúdo" particular das declarações. Estamos diante de 7 mil folhas de nomes, datas, relatos, memórias, entrelaçados numa trama de perguntas e respostas similares, estruturadas sob fórmulas que se repetem seguidamente. O que estou sugerindo é que o conhecimento sobre as instituições locais e o comportamento de seus funcionários diante do qual o julgamento ocorre parece se perder, ou ficar em segundo lugar, frente ao protagonismo que assumem a formalidade e as convenções destes documentos jurídicos.

Entretanto, este fato não invalida a contundência de sua presença: temos diante de nós um extenso expediente onde foram registradas as vozes de mais de cem vizinhos que deram conta do acontecido na ordem política local e regional durante o mandato de um governador. Esse documento é indicador dessas histórias locais - diversas, particulares, ancoradas em problemáticas próprias de cada cidade - que, desde então, ficaram contidas em um relato mais amplo, de escala regional. E poderia se dizer que esse corpus por si mesmo indica a dimensão do poder estatal para intervir, investigar e elaborar informações sobre seus domínios coloniais, contribuindo nesse processo para reafirmá-lo. Isto é, para além do uso efetivo que fizeram desses textos, sugiro que sua eficácia não residia tanto nas informações ali contidas, e sim na sua própria produção como parte da ação de constituição da autoridade régia sobre as colônias.

Nas últimas páginas do expediente, o juiz de residencia, dirigindo-se ao Conselho das Índias, queixava-se dos obstáculos que os funcionários locais impuseram para que pudesse cobrar os custos e multas do julgamento. Levara oito meses tentando arrecadar o dinheiro, parte do qual correspondia a seu salário, sem resultado algum. Assinalava também que 60 dias eram insuficientes para realizar devidamente o processo judicial.

O expediente foi enviado ao Conselho das Índias que era, junto ao Rei, o órgão supremo de governo para os domínios americanos do império espanhol. Encontram-se arquivadas apenas algumas anotações "formais" instruídas por seus funcionários, com as quais se dá por finalizado o processo. Em I792 (quase 30 anos depois do julgamento e quase 40 do fim do mandato de Tineo!) se confirmaram as sentenças pronunciadas por Azebey, indicando que "em 
respeito ao tempo transcorrido desde que se deram aquelas e vieram os autos ao Conselho, arquivam-se na escrivaria da Câmara". ${ }^{\text {I9 }}$ Não temos notícias se o documento foi lido, questionado ou discutido no Conselho das Índias.

Em contraposição, sim, temos informações de que parte desse extenso expediente ficou depositada nos arquivos dos cabildos, disponível para leitura e ao possível uso que poderia lhe dar algum juiz de uma futura residencia. ${ }^{20}$ Nesse sentido, a partir da investigação desenvolvida em Córdoba, Azebey elaborou um documento chamando a atenção aos cabildantes sobre as deficiências registradas na administração do governo local. Ali também anotou uma série de medidas para resolver estes problemas. Ordenou que esse texto fosse copiado no livro do cabildo "para que em todo tempo conste e se faça saber aos alcaides ordinários, ao tempo eles sejam recebidos [ou seja, quando tomem posse dos cargos], para que não aleguem ignorância" (grifo meu). ${ }^{2 I}$ Nesse caso, o juiz assinalava problemas que persistiam e exortava ao cabildo "atual" e aos funcionários que seriam incorporados em um futuro a adequar sua conduta às normas que estava fixando por escrito. Dez anos depois, na residencia posterior, o juiz encarregado deste processo recuperou esse mesmo documento - que efetivamente foi copiado nos livros do governo - para apontar a displicência que permaneceu na administração do cabildo cordobês e reafirmar o dever de cumprir as ordens ditadas por seu antecessor.

\section{ORALIDADE E ESCRITA: UM TEMPO FABRICADO?}

Este artigo buscou aproximar-se dos modos em que a categoria tempo foi construída e representada no contexto de um juicio de residencia, por meio do exame dos usos e das implicações da oralidade e da escrita. Nesse trajeto, parte da reflexão se centrou na análise do relato escrito resultante da residencia como uma ação significativa e cujo produto é um texto que ultrapassa a situação social a que faz referência. Se Leach (2000 [1966]) buscou assimilar os ritos aos mitos, neste caso estamos operando de modo inverso, assimilando um texto a uma ação ritual. As páginas anteriores constituem uma tentativa de divisar abordagens e perguntas possíveis, ensaiando uma análise que permita vislumbrar quais outros sentidos ou implicações assumia o processo de elaboração desse expediente.

Situei a realização da residencia em termos de um tempo presente, o tempo da ação, do que está acontecendo. A residencia de Tineo foi mais uma entre várias, porém era única como cada uma delas. A conjuntura se revelou nos conteúdos e formas particulares que essa mesma residencia adotou em cada cidade e na individualidade dos sujeitos declarantes e seus depoimentos. Entretanto, esse processo se organizou a partir de determinadas pautas e foi escrito segundo uma estrutura que homogeneíza e sistematiza o que foi dito e feito durante o julgamento. Nesse tempo "presente" se opera a transformação 
da oralidade à escrita. A residencia se desenvolve e ao mesmo tempo vai se inscrevendo em um texto.

A partir dessa perspectiva temporal, a residencia volta sobre o passado e olha também para o futuro: o passado aparece e se constrói especialmente através do relato oral das testemunhas, enquanto o tempo por vir é visualizado ou concebido ao fixar os relatos por escrito. O caráter efêmero da residencia e da oralidade se opõe à permanência de um documento que poderá ser lido e utilizado no futuro. Trata-se de um texto que é um objeto, uma espécie de obra em vários volumes, que impõe sua presença material, que tem espacialidade, que conserva os traços físicos do transcurso do tempo e cujos milhares de páginas indicam que ali ficou um registro de um momento da história. Se o passado é construído por meio da oralidade e o presente configura o tempo em que a ação de escrever fixa esse passado, o futuro torna-se visível e palpável prevendo a permanência desse objeto que é o texto.

A residencia supunha um exercício de sistematizar, classificar e comprimir sob certos moldes - próprios de um poder centralizado - a dinâmica e heterogênea sociedade colonial. De acordo com a análise desenvolvida, o tempo parece não ter escapado a essa mesma lógica. O julgamento se realizava quando encerrava o mandato de um governador; seu desenvolvimento perturbava os ritmos cotidianos e o espaço em que operava estava definido em termos da jurisdição provincial (limites que o mesmo processo ajudava a construir). O juiz tinha competências sobre o tempo correspondente ao mandato do governador residenciado, o interrogatório e o expediente eram construídos como uma metáfora da organização política local, e a escrita recuperava e fixava o relato oral e individual dos declarantes num objeto. As sociedades locais aparecem sujeitadas aos tempos do Estado, ajustando a ele suas memórias e seus ritmos. O recorte do passado imposto pela residencia dava maior visibilidade a uma marcação temporal que era comum nessa sociedade e que remetia justamente aos períodos definidos pelos mandatos dos governadores. A exploração de outras instituições, como os cabildos e as visitas, poderia dar conta de outros modos de registrar e contabilizar o tempo.

Se este trabalho aponta para diversas maneiras de avançar no estudo da categoria tempo por meio da análise de uma instituição jurídica e política do governo hispânico colonial, a distinção entre oralidade e escrita contribuiu para elucidar os diferentes modos de construir e representar o passado e o futuro. Neste trajeto, a análise também foi revelando indícios de como esses registros se complementavam, interatuavam ou se modificavam, sugerindo a potencialidade de continuar aprofundando o exame sobre as relações entre estes domínios. Entendemos que a ampliação do corpus documental e do espaço institucional poder vir a lançar luz sobre outras temporalidades que organizavam e orientavam a experiência humana na sociedade colonial. 
Silvina Smietniansky é doutora em Antropologia pela Universidade de Buenos Aires. É pesquisadora do Centro de Estudios en Historia, Cultura y Memoria da Universidade Nacional de Quilmes/Consejo Nacional de Investigaciones Científicas y Técnicas, e autora de Ritual, tiempo y poder - Una aproximación antropológica a las instituciones del gobierno colonial (Gobernación del Tucumán, siglos XVII y XVIII) (20I3). 


\section{NOTAS}

* Agradeço a Mariza Peirano pelas suas valiosas leituras e comentários, também aos integrantes do Núcleo de Antropologia da Política (Museu Nacional/UFRJ), onde tive a possibilidade de discutir uma primeira versão deste texto, e aos pareceristas anônimos pelas suas sugestões.

I Existe uma vasta literatura sobre este tema em contextos coloniais, incluindo o espaço da América hispânica. Diversos estudos ao indagar como a oralidade e escrita se combinam, se complementam ou entram em tensão em diferentes âmbitos da vida social, contribuem para enriquecer as análises e historicizar as relações entre ambos os registros (Messick, I989, I996; Mignolo, I992; Trajano, I993a, I993b, 2000; Molinié, I997; Schieffelin, 2002; Martínez Sagredo, 2008, 20I I; Martínez \& Martínez, 20I3). O segmento de instituições jurídico-políticas inscritas no marco de Direito Indiano e na "cultura jurídica" que se configurou na América colonial também marcam outra série particular de produções sobre essa matéria (Hespanha, 2005; Martínez Martínez, 2006; Dougnac, 2006; Miceli, 2008; Fernández Alcaide, 2008; González Undurraga, 2012). Estas referências bibliográficas não definem um estado da arte exaustivo, mas um recorte parcial ligado ao problema e à orientação de uma pesquisa que segue em curso.

2 Os trabalhos de Clifford Geertz (2000 [I98I]) e Marshall Sahlins (I988 [I985]) constituem duas referências clássicas que examinam e ilustram, com seus respectivos casos de análises, as potencialidades e particularidades de uma abordagem etnográfica ao estudo de fontes históricas e acontecimentos passados. A antropologia contribuiu com outras perspectivas de análises, modelos teóricos e novas abordagens no exame dos temas que os historiadores pesquisaram e focalizaram - este aporte é claro, por exemplo, no campo do parentesco e no estudo dos rituais (Cohn, I980; Darnton, I987 [I984]; Thompson, I992 [I976]; Viazzo, 2003). Por outro lado, os novos estudos da Antropologia da Escrita analisam eventos das sociedades ocidentais contemporâneas (Barton \& Papen, 20I0; Fraenkel, 20Io). No que diz respeito ao tipo de documentação oficial e burocrática, como a que este artigo examina, nos últimos tempos a antropologia vem pesquisando a significação e 
a eficácia não apenas dos documentos, mas também do mesmo processo de sua fabricação e circulação dentro de diversos tipos de instituições de governo (Navaro-Yashin, 2007; Hull, 201 2; Lowenkron \& Ferreira, 20I4).

3 Este artigo dá continuidade às aproximações ao estudo do tempo e à história elaboradas em trabalhos anteriores (Smietniansky, 2010, 2013). A ampliação destas abordagens se desenvolve a partir da incorporação das perspectivas de Jakobson, Peirce e Austin. Tive oportunidade de refletir e discutir as ideias destes autores durante o projeto de pesquisa de pós-doutorado no PPGAS/DAN da Universidade de Brasília (20I3-20I5).

4 O status de vecino era a condição necessária para ocupar um cargo no governo local e implicava uma distinção particular dentro do setor hispano-crioulo. Este status requeria a posse de uma casa habitada na cidade, a chefia da família e o consentimento de seus pares vecinos; ademais, o casamento com uma mulher espanhola ou crioula no caso de ser estrangeiro.

5 Neste artigo as referências às fontes estão circunscritas ao problema do tempo. Em Smietniansky (2012) está disponível uma transcrição de parte do documento e, em Smietniansky (20I3), uma descrição completa inclui um exame comparativo dos feitos e testemunhos registrados nas diferentes cidades.

6 Neste período a província de Tucumán formava parte do Virreinato do Peru, com capital em Lima, e ficava sob a órbita judicial e administrativa da Audiência de Charcas (atual Sucre). Estava constituída pelas cidades de Salta (sede do governo), Córdoba (sede episcopal), Tucumán, Jujuy, Santiago del Estero, Catamarca e La Rioja. De acordo com a estrutura institucional castelhana, cada distrito contava com seu cabildo que formava o governo local encarregado de administrar diferentes aspectos da vida social, política e econômica da comunidade. Os cargos públicos constitutivos do cabildo eram os "alcaides ordinários" de primeiro e segundo voto. Eles eram eleitos anualmente, administravam a justiça em primeira instância e sem a presença de ao menos um deles não se podia reunir o cabildo.

7 Os aportes da Antropologia da Escrita e as abordagens etnográficas desenvolvidas recentemente nas análises dos 
documentos também são inspiradores. Ver a nota 3 para referências.

8 No Brasil, Moacir Palmeira (200I) examinou a noção de "tempo de" a partir da categoria "tempo da política", utilizada entre as populações campesinas do Nordeste.

9 "Siendo siete las ciudades por más desvelo y esmero que ponga un juez no es posible poder verlo todo en tan corto tiempo para cumplir con su obligación y descargo de su conciencia, ni los pobres, principalmente los indios de encomienda, y mujeres desvalidas exponen sus quejas a los comisionados, que son del mismo Pays, y emparentados con los jueces ordinarios, temerosos de no ser oídos y de experimentar mayores extorsiones como lo experimenté después de sentenciada la residencia con la ocasión de haber visitado algunas ciudades". AHN, Consejos, 20375, exp. I, Pieza 9, f. 3v-4r.

Io A estes caberia incluir outros declarantes consultados na posterior pesquisa pública.

I I AHN, Consejos, 20374, exp. I, Pieza 3, f. I4r-Igr.

I 2 O juramento constitui uma instituição jurídica e religiosa que, enquadrada na tradição judaico-cristã, comporta uma relação de correspondência entre as palavras e as coisas, no sentido de que aquele se realiza através das palavras proclamadas, aproximando-se da linguagem divina que tem a força de criar ao dizer (Agamben, 20Io).

I3 AHN, Consejos, 20374, exp. I, Pieza I, f. I9IV-I98v.

I4 AHN, Consejos, 20375, exp. I, Pieza 7, f. 8Ir.

I5 AHN, Consejos, 20375, exp. I, Pieza 7, f. I25r.

I6 AHN, Consejos, 20375, exp. I, Pieza 7, f. I6gr.

I7 AHN, Consejos, 20375, exp. I, Pieza 6, f. 3I7V.

I 8 AHN, Consejos, 20374, exp. I, Pieza 5, f. 85v-86v.

I9 AHN, Consejos, 20375, exp. I, Pieza 9, f. 3V.

20 Quando os juízes visitavam as prisões e examinavam os livros do cabildo, costumavam pedir os relatórios que tinham elaborado os magistrados na residencia anterior. Em alguns casos, os cabildos contavam com esses informes.

2I AHN, Consejos, 20375, exp. I, Pieza 8, f. 398r-398v. 


\section{REFERÊNCIAS BIBLIOGRÁFICAS}

Archivo Histórico Nacional, Madrid. I753-I792. Residencia de Juan Martínez de Tineo, gobernador de Tucumán. Consejos, 20374, expediente I; Consejos, 20375, expediente I.

Agambem, Giorgio. (2010). El sacramento del lenguaje. Arqueología del juramento. Buenos Aires: Adriana Hidalgo Editora. Austin, John L. (1975). How to do things with words. Cambridge, MA: Harvard University Press.

Barton, David \& Papen, Uta. (20I0). What is the anthropology of writing? In: Barton, David \& Papen, Uta (orgs.). The anthropology of writing: understanding textually mediated worlds. Londres: Continuum International Publishing Group, p. 3-32.

Cohn, Bernard S. (I980). History and anthropology: the state of play. Comparative Studies on Society and History, 22, p. I98-22I.

Darnton, Robert. (I994). La gran matanza de gatos y otros episodios en la historia de la cultura francesa. México: Fondo de Cultura Económica.

Dougnac, Antonio. (2006). Los principios clásicos del procedimiento y la palabra hablada en el sistema jurídico indiano al estilo de Chile. Revista de Estudios Histórico Jurídicos, 28, p. 425-490.

Durkheim, Émile. (2007 [I9I 2]). Las formas elementales de la vida religiosa. Madrid: Akal.

Durkheim, Émile \& Mauss, Marcel (I97 I [1903]). De ciertas formas primitivas de clasificación. Contribución al estudio de las representaciones colectivas. In: Mauss, Marcel. Instituciones y culto. Obras II. Barcelona: Barral Ediciones.

Evans-Pritchard, Edward Evan. (I977 [I940]). Los Nuer. Barcelona: Anagrama.

Fabian, Johannes. (1983). Time and the other. How anthropology makes its object. Nova York: Columbia University Press. Fernández Alcaide, Marta. (2008). Textos de compra-venta en el siglo XII. Lexis, XXXII/2, p. 223-250.

Finnegan, Ruth H. (1988). Literacy and orality: studies in the technology of communication. Nova York: Basil Blackwell. 
Fraenkel, Béatrice. (2010). Writing acts: when writing is doing. In: Barton, David \& Papen, Uta (orgs.). The anthropology of writing: understanding textually mediated worlds. Londres: Continuum International Publishing Group, p. 33-43.

Geertz, Clifford. (2000 [I98I]). Negara. El estado-teatro en el Bali del siglo XIX. Barcelona: Paidós.

Geertz, Clifford. (I992 [1973]). Persona, tiempo y conducta en Bali. In: La interpretación de las culturas. Barcelona: Gedisa, p. 299-238.

González Undurraga, Carolina. (2012). Lo verbal en lo letrado. Una reflexión a partir de los procedimientos judiciales (Chile, fines de la colonia y principios de la república). Nuevo Mundo Mundos Nuevos [online], Colloques. Disponível em: <http:// nuevomundo.revues.org/63570>. Acesso em 29 dez. 2014.

Goody, Jack. (2000). The power of the written tradition. Washington, DC: Smithsonian Institution Press.

Goody, Jack \& Watt, Ian. (2003 [1963]). Las consecuencias de la cultura escrita. In: Goody, Jack (org.). Cultura escrita en sociedades tradicionales. Barcelona: Gedisa, p. 39-82.

Guevara-Gil, Armando \& Salomon, Frank. (I994). A "personal visit": colonial political ritual and the making of Indians in the Andes. Colonial Latin American Review, 3/1-2, p. 3-36.

Herzog, Tamar. (2000). Ritos de control, prácticas de negociación: pesquisas, visitas y residencias y las relaciones entre Quito y Madrid (I650-I750). Madri: Fundación Histórica Tavera.

Hespanha, António Manuel. (2005). As fronteiras do poder. O mundo dos rústicos. Sequência, 51, p. 47-105.

Hull, Matthew. (20I 2). Documents and bureaucracy. Annual Review of Anthropology, 4I, p. 25I-267.

Jakobson, Roman. (I97I). Selected writings. The Hague: Mouton (vol. 2).

Koselleck, Reinhart. (2006 [1979]). Futuro passado. Contribuição à semântica dos tempos históricos. Rio de Janeiro: Contraponto/PUC-Rio.

Le Goff, Jacques. (I983 [I978]). Tiempo, trabajo y cultura en el Occidente medieval. Madri: Taurus.

Leach, Edmund. (2000 [1966]). Ritualization in man. In: HughJones, Stephen \& Laidlaw, James (orgs.). The essential Edmund Leach. Nova York: Yale University Press, p. I58-165 (vol. I). 
Leach, Edmund. (I97I [I96I]. Dos ensayos sobre la representación simbólica del tiempo. In: Replanteamiento de la antropología. Barcelona: Seix Barral, p. I92-2 Io.

Lowenkron, Laura \& Ferreira, Letícia. (20I4). Anthropological perspectives on documents. Ethnographic dialogues on the trail of police papers. Vibrant, II/2, p. 75-III.

Martínez C., José Luis \& Martínez S., Paula (2013). Narraciones andinas coloniales. Oralidad y visualidad en los Andes. Journal de la Société des Américanistes, 99/2, p. 4I-8I. Martínez Martínez, Faustino. (2006). El tránsito de la oralidad hacia la escritura en la experiencia jurídica del siglo XIII: ejemplo sajón e hipótesis castellana (parte primera). Cuadernos de Historia del Derecho, I3, p. I55-220.

Martínez Sagredo, Paula. (20 I I). Algunas reflexiones sobre las prácticas escriturarias en los Andes coloniales (siglo XVII). Atenea, 503, p. 93-I09.

Martínez Sagredo, Paula. (2008). La oralidad como instrumento para acceder al discurso andino colonial. El caso del Manuscrito de Huarochirí. Diálogo Andino, 32, p. 7-20.

Miceli, Paola. (2008). Representar, instituir, redimir: oralidad y escritura en los textos forales. Bulletin du Centre d'Études Médiévales d'Auxerre, Numéro Hors série 2. <http:// cem.revues.org/index9642.html>. Acesso em 23 dez. 2014. Messick, Brinkley. (1996). The calligraphic state. Textual domination and history in a Muslim society. Berkeley: University of California Press.

Messick, Brinkley. (I989). Just writing: paradox and political economy in Yemeni legal documents. Cultural Anthropology, 4/I, p. 26-50.

Mignolo, Walter. (I988). La cuestión de la letra en el Nuevo Mundo. Revista de Crítica Literaria Latinoamericana, I 4/28 (Historia, sujeto social y discurso poético en la colonia), p. 29-53.

Molinié, Antoinette. (I997). Buscando la historicidad andina: una propuesta antropológica y una memoria hecha rito. In: Varon Gabai, Rafael \& Flores Espinoza, Javier (orgs.). Arqueología, antropología e historia en los Andes. Homenaje a María Rostworowski. Lima: IEP - Banco Central de Reserva del Perú, p. 69i-708. 
Navaro-Yashin, Yael. (2007). Make-believe papers, legal forms and the counterfeit: affective interactions between documents and people in Britain and Cyprus. Anthropological Theory, 7, p. 79-98.

Palmeira, Moacir. (200I). Política e tempo: nota exploratória. In: Peirano, Mariza (org.). O dito e o feito. Ensaios de antropologia dos rituais. Rio de Janeiro: Relume Dumará, p. I7 I-I77.

Peirce, Charles. (I955). Logic as semiotic: the theory of signs; The principles of phenomenology; How to make our ideas clear. In: Philosophical writings of Peirce (seleção e edição de Justus Buchler). New York: Dover Publications. Peirano, Mariza. (200I). A análise antropológica de rituais. In: Peirano, Mariza (org.). O dito e o feito. Ensaios de antropologia dos rituais. Rio de Janeiro: Relume Dumará, p. I7-40. Peirano, Mariza. (I995). A favor da etnografía. Rio de Janeiro: Relume Dumará.

Rappaport, Joanne. (I987). Mythic images, historical thought, and printed texts: the Páez and the written word. Journal of Anthropological Research, 43/I, p. 43-6I.

Sahlins, Marshall. (I988 [1985]). Islas de historia. La muerte del Capitán Cook. Metáfora, antropología e historia. Barcelona: Gedisa.

Schieffelin, Bambi B. (2002). Marking time: the dichotomizing discourse of multiple temporalities. Current Anthropology, 43/4 (Número especial: Repertoires of Timekeeping in Anthropology), p. 5-I7.

Smietniansky, Silvina. (2013). Ritual, tiempo y poder. Una aproximación antropológica a las instituciones del gobierno colonial (Gobernación del Tucumán, siglos XVII y XVIII). Rosario: Prohistoria.

Smietniansky, Silvina. (20 I2). El estudio de las instituciones del gobierno colonial. Una aproximación etnográfica al juicio de residencia como ritual. Corpus. Archivos Virtuales de la Alteridad Americana, 2/I), p. I-32.

Smietniansky, Silvina. (2010). Tiempo y ritual. Una aproximación al análisis de las representaciones del orden en la sociedad colonial (Gobernación del Tucumán, siglos XVII y XVIII)". Revista del Museo de Antropología, 3, p. 99-I I 2. 
Tambiah, Stanley. (1985). Culture, thought and social action. Cambridge: Harvard University Press.

Thompson, Edward P. (I992 [I976]). Folklore, antropología e historia social. Entrepasados. Revista de Historia, II/2, p. 63-86.

Thompson, Edward P. (I967). Time, work-discipline, and industrial capitalism. Past and Present, 38/I, p. 56-97.

Trajano Filho, Wilson. (2000). Outros rumores de identidade na Guiné-Bissau. Série Antropologia, 279. Departamento de Antropologia/Universidade de Brasília.

Trajano Filho, Wilson. (I993a). Rumores: uma narrativa da nação. Série Antropologia, I43. Departamento de Antropologia/Universidade de Brasília.

Trajano Filho, Wilson. (I993b). Escrita e oralidade: uma tensão na hegemonia colonial. Série Antropologia, I54. Departamento de Antropologia/Universidade de Brasília.

Viazzo, Pier Paolo. (2003). Introducción a la antropología histórica. Lima: PUC/ Instituto Italiano de Cultura. 


\section{TEMPO, ORALIDADE E ESCRITA: A SOCIEDADE HISPANO-COLONIAL ATRAVÉS DO ESTUDO DE UM PROCEDIMENTO JUDICIAL}

Resumo

Este artigo aborda as experiências e perspectivas locais da categoria tempo nos territórios austrais e periféricos do império espanhol na América. A partir do exame da documentação de um processo de juicio de residencia dirigido a um governador da província de Tucumán em I763-I764, indaga-se de que modo a oralidade e a escrita operavam na construção e representação do passado, do presente e do futuro. Enquanto o julgamento se realizava, o registro transformava a palavra oral em texto escrito. $\mathrm{O}$ artigo examina como o passado era construído por meio de testemunhos orais, como o presente configurava o tempo em que a ação de escrever fixava esse passado, e como o futuro tornava-se palpável pela permanência do objeto-texto. Esta abordagem envolve uma reflexão sobre a escrita desse expediente como uma ação significativa, cujo valor ia além do conteúdo referencial do discurso.

\section{TIME, ORALITY AND WRITING: HISPANIC COLONIAL SOCIETY THROUGH THE LENS OF A COURT CASE}

This article proposes an approach to the study of local perspectives and experiences of time in the American austral territories of the Spanish Empire. By examining the record written during the juicio de residencia impeached to a governor of the province of Tucumán in I763-1764, it analyzes in which ways orality and writing operated in the construction and representation of the past, the present and the future. While the trial was celebrated it was also transformed into a written text, leading the words from orality to writing. The article explores how the past was constructed through the oral testimonies, the way the present was configured as a time in which the act of writing fixed that past, and the future became visible by the permanence of the text-object. This approach involves a reflection on the act of writing in which its value is beyond the referential content of the text.

\section{Palavras-chave}

Tempo;

Oralidade;

Escrita;

Juicio de residencia;

Sociedade hispano-colonial.
Keywords

Time;

Orality;

Writing;

Juicio de residencia;

Hispanic colonial society. 